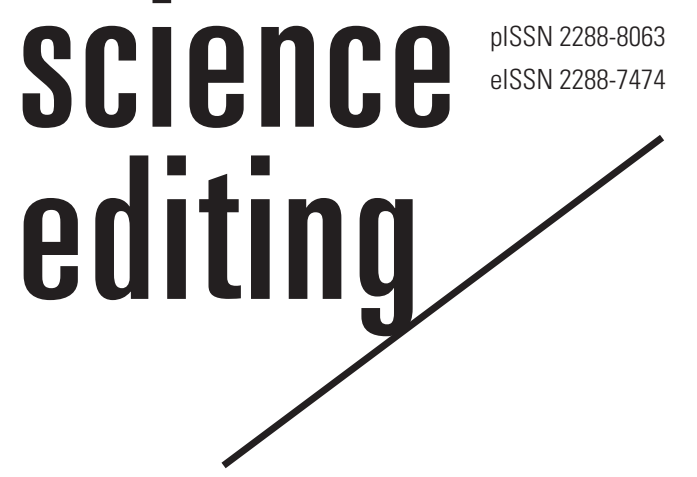

\title{
How to archive scholarly journals from the Republic of Korea in the National Library of Korea
}

\author{
Sun Huh
}

Department of Parasitology and Institute of Medical Education, College of Medicine, Hallym University, Chuncheon, Korea

\begin{abstract}
According to the policies of a number of indexing database agencies and the Principles of transparency and best practice in scholarly publishing 3rd version, archiving of scholarly journal articles is mandatory for editors and publishers. Furthermore, publishers in Korea have been required to deposit journal article files in the National Library of Korea since February 2016 by law. This study presents background information on archiving sites and how to deposit digital files in the Library's archive. Although some archiving sites for scholarly journals have been developed internationally, it may be burdensome for publishers in Korea (almost all of which are academic societies) to use those sites to deposit digital files because a deposit fee is required by some agencies. Furthermore, PubMed Central, maintained by the United States National Library of Medicine, accepts only English-language biomedical journals. In contrast, it is possible for publishers to deposit articles in the National Library of Korea by uploading files without any fees, regardless of the journal language. Furthermore, publishers can select the access policy of their journals. All journal publishers and editors in Korea are recommended to utilize the archiving site of the National Library of Korea to preserve their journal articles.
\end{abstract}

Keywords

Archives; National Library of Korea; Republic of Korea; Scholarly communication; Scholarly journals

\section{Introduction}

Accepted: July 17, 2019

Correspondence to Sun Huh shuh@hallym.ac.kr

ORCID

Sun Huh

https://orcid.org/0000-0002-8559-8640
The Encyclopedia Britannica defines the term "archives" as follows: "Archives, also called records or record office, repository for an organized body of records produced or received by a public, semipublic, institutional, or business entity in the transaction of its affairs and preserved by it or its successors. The term archives, which also designates the body of records themselves ..." [1]. In journal publishing, "archiving" implies preserving the print version of 
journal documents, which can be found in libraries. After scholarly journals started to be published in a digital format in the 1990s and internet access became widespread, the concept of "archive" has come to refer to digital archives. Both international journals and domestic journals from Korea began to publish online versions with unique International Standard Serial Number (ISSN, Online). Furthermore, online-only journals (without a print version) emerged and were established as a good business model, as exemplified by the BMC and PLoS series of journals. Several online-only journals are also published in Korea, with a noteworthy example being the Journal of Educational Evaluation for Health Professions, which was converted from a print journal to an online-only journal in 2006 [2]. However, the main problem with online-only journals, or journals with online versions, is the accessibility of the content if the journal stops being published for any reason. If the journal homepage disappears, it becomes impossible to access its contents. Therefore, digital archiving of scholarly journals became an important matter.

Furthermore, archiving became an essential requirement for being listed in several abstracting and indexing databases. First, the Directory of Open Access Journals (DOAJ) listed the presence of an archiving site as an evaluation item for open access journals. DOAJ strongly recommends that journal content be preserved through a dedicated digital archiving and preservation service, sometimes referred to as long-term preservation and archiving [3]. Second, the pre-evaluation list for Scopus submission also includes archiving, as follows: "7.7 A journal's plan for electronic backup and preservation of access to the journal content in the event a journal is no longer published (access to archive) is clearly indicated at journal's website" [4]. Third, as a prerequisite for application to PubMed Central, the United States National Library of Medicine looks for ongoing publisher conformance with the Principles of transparency and best practice in scholarly publishing [5]. Of the 16 items included the Principles of transparency and best practice in scholarly publishing 3rd version, archiving is the 13th item, as follows: "A journal's plan for electronic backup and preservation of access to the journal content (for example, access to main articles via CLOCKSS or PubMed
Central) in the event a journal is no longer published shall be clearly indicated" [6]. Therefore, verification of the archiving site is mandatory to be a PubMed Central journal.

\section{What Repository Sites Exist for Digital Archiving of Scholarly Publishing?}

In the Keepers Registry, the following repositories are listed for electronic journals [7]: Archaeology Data Service, British Library, CLOCKSS Archive, Cariniana Network in Brazil, eDepot in Netherlands, Global LOCKSS Network, HathiTrust, United States Library of Congress, National Digital Preservation Program in China, PKP Preservation Network, Portico, Scholars Portal of Ontario Council of University Libraries, and the Swiss National Library. According to the information provided by the above agencies, the United Kingdom, Netherlands, and Switzerland are countries with mandatory deposit of e-journals in the national libraries' archives. The United States requires electronic-only journals to be deposited in the Library of Congress. Of the above 14 agencies, the following repositories in Table 1 are generally open to scholarly journals from around the world.

Besides the above agencies, PubMed Central is a wellknown archiving site; however, it only accepts English-language biomedical journals. Although there were 133 journals from Korea listed in PubMed Central through June 2019, issues in Korean before journals changed their language to English-only cannot be listed in PubMed Central. Those issues should be deposited in another archiving site.

\section{Why Was a Law Mandating Digital Archiving Established in Korea?}

In February 2016, Korean Government revised the Library Act as follows to mandate that online publications of books and periodicals be deposited in the archive of the National Library of Korea [8]:

Article 20 (Legal Deposit of Library Materials)

(1) When anyone has published or produced a library materi-

Table 1. Archiving agencies that generally accept e-journals from all over the world

\begin{tabular}{|c|c|c|c|c|}
\hline Archiving agencies & Contents & Access & $\begin{array}{l}\text { Payment for } \\
\text { deposit }\end{array}$ & URL \\
\hline CLOCKSS Archive & Digital scholarly materials & $\begin{array}{l}\text { Freely available, when content is not available } \\
\text { from a publisher }\end{array}$ & Required & http://www.clockss.org/ \\
\hline Global LOCKSS Network & E-journals, e-books & Accessible whenever the content is unavailable & Required & http://www.lockss.org/ \\
\hline Portico & $\begin{array}{l}\text { E-journals, e-books, and other } \\
\text { electronic scholarly content }\end{array}$ & Access at participating institutions & Required & http://www.portico.org/ \\
\hline
\end{tabular}


al (excluding online but as prescribed in Article 21, including those to which international standard book or serial numbers are assigned under Article 21 shall be included; hereafter the same shall apply in this Article), he/she shall make a legal deposit of such library materials to the National Library of Korea within 30 days from the date such library material is published or produced. The same shall apply when he/she publishes or produces a revised and enlarged edition. < Amended by Act No. 9528, Mar, 25, 2009; Act No. 13960, February 3, 2016> (2) Where the State, a local government, or any other public institution prescribed by Presidential Decree makes a legal deposit of library materials to the National Library of Korea pursuant to paragraph (1), it shall ensure such legal deposit in digital file format as prescribed by Presidential Decree. < Newly Inserted by Act No. 13960, February 3, 2016>

This law was revised to ensure the long-term preservation of digitally published files whenever a publisher goes out of business or journals or magazines stop being published for any other reason. An announcement was made stating that the National Library of Korea will play the role of an archiving site for digital publications, including scholarly journals from both private and public publishers. Therefore, all scholarly journal publishers in Korea, most of which are academic societies, should deposit their electronic journals to the National Library of Korea within 30 days after publication. Journal publishers can also deposit their digital files to the CLOCKSS Archive, Global LOCKSS Network, and Portico. However, payment is required to preserve digital files with those archiving agencies, whereas no fee is required to deposit journal files in the National Library of Korea because it is a governmental organization.

\section{How to Deposit Journals' Digital Files in the National Library of Korea Archive}

The publisher should visit the bibliographic information system (Fig. 1) [9]. To upload a file, click "periodical submission" and then click "online data submission." After that, login is required to upload digital files. There is no clear indication of which digital file format is most suitable (e.g., PDF, ebook 3.0, JATS XML, LaTeX, or other file formats); however, uploading PDF files is generally accepted. If uploading the digital files is difficult or there are too many files to upload using this interface, they can be submitted via email, as indicated in the agreement form. Before submitting digital files, publishers should sign an agreement form with the National Library of Korea (Suppl. 1), describing the journal title, author (= publisher), publisher, date of publication, and eISSN. Furthermore, accessibility from outside of the National Library of Korea should be indicated. If publisher does not want to allow access to the digital files outside of the Library, "access only in

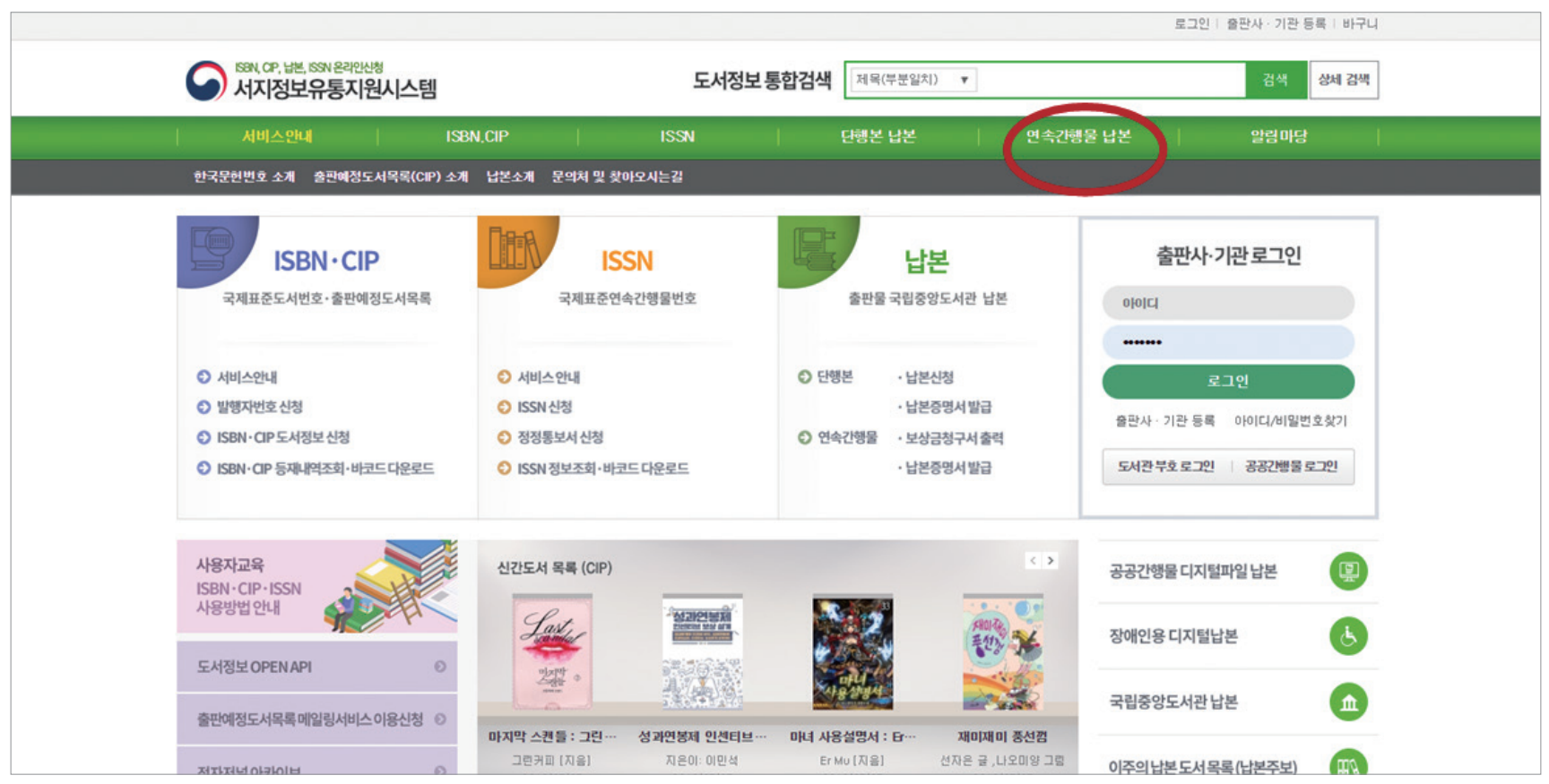

Fig. 1. Screenshot of the bibliographic information system of the National Library of Korea (http://seoji.nl.go.kr/index.do). To upload a file, click "periodical submission" (red circle), and then click "online data submission." After that, login is required to upload digital files. 
the National Library of Korea" should be chosen. If a journal ceases to be published, its digital content will be available according to the access policy of the journal. If it is not an open access journal, it will only be available at the National Library of Korea. Although some society-owned journals are published by international commercial publishing companies not located in Korea, digital archiving in the National Library of Korea is mandatory. If digital files are submitted successfully, that information is presented in a list contained on the site [10], where it will be possible to check which journals have been archived.

\section{Policies of the National Library of Korea as an Archiving Agency According to Common Explanatory ltems of the Keepers Registry}

The following suggestions can be made.

Overview and background: The National Library of Korea is the archiving site for scholarly electronic journals published in Korea. It is supported by the Library Act of the Korean Government revised in February 2016 that mandates digital file deposit of publications in the National Library of Korea.

Ingest and preservation workflow: Content that has been preserved in an archiving site of the National Library of Korea shall be maintained.

Library access to content: If the publisher selects open access, the content can be accessed from outside the Library. If not, it is only available inside the Library. Whenever publishing ceases, the accessibility is same as the publisher's previously chosen option.

Auditing of content, policies, and procedures (both internal and external activities): All ingested files are recorded in the catalog upon ingestion.

The policies suggested above should be implemented by the National Library of Korea. Furthermore, it is necessary for the Library to be listed in the Keepers Registry, like other national libraries in the United States, United Kingdom, Netherlands, and Switzerland [7].

\section{Conclusion}

In scholarly journal publishing, archiving of digital files is mandatory. According to the Library Act, all scholarly journal publishers in Korea must deposit journal article files in the National Library of Korea starting in 2016. It is easy and simple to participate in digital archiving after signing the agreement form. I hope that all publishers and editors in Korea take advantage of this opportunity to deposit journal article files in the Library, which will enable them to announce the archiving site used by their journals.

\section{Conflict of Interest}

No potential conflict of interest relevant to this article was reported. It is not an official opinion of the National Library of Korea.

\section{Supplementary Material}

Supplementary file is available from https://doi.org/10.6087/ kcse. 180

Suppl. 1. Agreement form for archiving between a publisher and the National Library of Korea.

\section{References}

1. Encyclopaedia Britannica. Archives [Internet]. Chicago: Encyclopaedia Britannica [cited 2019 Jul 5]. Available from: https://www.britannica.com/topic/archives

2. Huh S. To broaden the horizon of the Journal of Educational Evaluation for Health Professions. J Educ Eval Health Prof 2006;3:1. https://doi.org/10.3352/jeehp.2006.3.1

3. Directory of Open Access Journals. Information for publishers [Internet]. [place unknown]: Directory of Open Access Journals [cited 2019 Jul 5]. Available from: https:// doaj.org/publishers\#applying

4. Elsevier. Pre-evaluation of Scopus submission [Internet]. Amsterdam: Elsevier [cited 2019 Jul 5]. Available from: https://www.readyforscopus.com/

5. National Center for Biotechnology Information. Policies: publisher practices [Internet]. Bethesda: US National Library of Medicine [cited 2019 Jul 5]. Available from: https:// www.ncbi.nlm.nih.gov/pmc/about/guidelines/\#pubpract

6. Directory of Open Access Journals. Principles of transparency and best practice in scholarly publishing 3rd version [Internet]. [place unknown]: Directory of Open Access Journals; 2018 [cited 2019 Jul 5]. Available from: https:// doaj.org/bestpractice

7. The Keepers Registry [Internet]. Edinburgh: The Keepers Registry [cited 2019 Jul 5]. Available from: https://thekeepers.org/

8. Korea Law Translation Center. Library Act [Internet]. Sejong: Korean Legislation Research Institute; 2018 [cited 2019 Jul 5]. Available from: https://elaw.klri.re.kr/kor_service/lawView.do?hseq=46323\&lang=ENG

9. Bibliographic information supporting system [Internet]. Seoul: National Library of Korea [cited 2019 Jul 5]. Available from: http://seoji.nl.go.kr

10. National Library of Korea E-journals Archive [Internet]. Seoul: National Library of Korea [cited 2019 Jul 5]. Available from: http://seoji.nl.go.kr/archive 